\title{
Review of Dolomite as Precursor of Geopolymer Materials
}

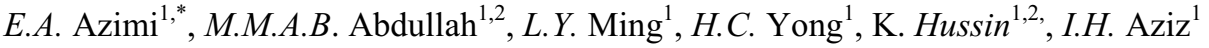 \\ ${ }^{1}$ Center of Excellence Geopolymer and Green Technology, School of Materials Engineering, Universiti \\ Malaysia Perlis (UniMAP), P.O. Box 77, D/A Pejabat Pos Besar, 01000, Kangar, Perlis, Malaysia \\ ${ }^{2}$ Faculty of Engineering Technology, Universiti Malaysia Perlis (UniMAP), P.O. Box 77, D/A \\ PejabatPosBesar, Kangar, Perlis 01000, Malaysia
}

\begin{abstract}
Geopolymer is an environmentally friendly cementitious binder that does not require the existence of ordinary Portland cement (OPC). Geopolymer has many excellent advantages, including high early strength, low shrinkage, good thermal resistance and good chemical resistance. Previous commonly used materials include fly ash, clay and slag. The used of dolomite as precursor material in geopolymer field is still new and at the early stage of study. Only a few researchers have done studies on dolomite in geopolymer. Dolomite $\left(\mathrm{CaMg}\left(\mathrm{CO}_{3}\right)_{2}\right)$ is abundant and generally inexpensive natural minerals. The possible use of these bulk calcium carbonate materials in improving the mechanical properties of geopolymers will therefore be of great interest. This paper summarizes some research outcomes on dolomite in geopolymer along with the potential of dolomite as geopolymer composites.
\end{abstract}

\section{Introduction}

The demand of the usage of concrete continues to increase along with the increasing demand of infrastructures. Traditionally, ordinary Portland cement (OPC) has been used as the binder in concrete. However, cement production involves the emission of considerable amount of greenhouse gases. Therefore, the development of alternative binders that can utilize industrial by-products is considered vital in order to help reducing the carbon footprint produced during cement production [1].

Geopolymers are class of binder materials that is formed by the activation of aluminosilicate materials with alkaline or alkaline-silicate solutions and it was first named and introduced by Davidovits[2]. Geopolymers which are also known as an inorganic polymers or alkali-activated binder have rapidly gained worldwide interests [3]. Geopolymers are amorphous to semi-crystalline three-dimensional silica-aluminate materials. They are prepared by mixing and activating the aluminosilicate sources such as fly ash, metal slag, kaolin or metakaolin and dolomite with alkaline liquid (sodium

\footnotetext{
*Corresponding author: emyaizat@gmail.com
} 
hydroxide and/or sodium silicate) and curing at a moderate temperature [4]. Geopolymers are classified as one of the green materials that contain many exceptional properties such as high compressive strength, low shrinkage, fire and acid resistant [5]. These geopolymer materials are able to offer comparable performance to the traditional cementitious binders in a wide range of applications, but with the additional advantage of lower greenhouse emissions [6]. Geopolymer technology is also increasing attention because it provides viable economical alternative to organic polymers and inorganic cements in diverse applications, such as refractory adhesives and materials[7]. These concern are also due to their excellent mechanical strength, adhesive behavior, long-term durability and exceptionally high thermal and chemical stability [8].

Silica (Si) and aluminum (Al) contents are the important compoundsin the raw material to be used and turned into geopolymer. The higher the silica and aluminum contents, the effectiveness of the geopolymers is higher. Besides, Davidovits[9] noted that the increasing in $\mathrm{Si}: \mathrm{Al}$ ratio can lead to the improvement of the fire and heat resistant characteristics. One of the studies done by Temuujin et al. [10] stated that fly ash geopolymers with Si/Al molar ratio of 3.5 displayed strong adhesion to steel substrates and has promising fire resistant characteristics.

The use of dolomite in geopolymer is still new and still at the early stage of study. The current work therefore investigates the effect of the addition of larger quantities of dolomite on geopolymerization, geopolymer microstructure, long-term strength development and shrinkage properties of geopolymer mortars [11].In this paper, the properties and the suitability of dolomite as geopolymers' precursor materials are reviewed.

\section{Methodology}

\subsection{Alkaline Solution}

Alkaline solution is one of the important parts in producing geopolymer. The main criteria for developing stable geopolymer are that the source materials must be highly amorphous and possess sufficient reactive glassy content, low water demand and be able to release aluminum easily. The alkaline activators such as sodium hydroxide $(\mathrm{NaOH})$, potassium hydroxide $(\mathrm{KOH})$, sodium silicate $\left(\mathrm{Na}_{2} \mathrm{SiO}_{3}\right)$ and potassium silicate $\left(\mathrm{K}_{2} \mathrm{SiO}_{3}\right)$ are used to activate aluminosilicate materials[12, 13]. Upon mixing alkaline activator with the aluminosilicate-reactive material (raw material),alkaline activating solution dissolve the $\mathrm{Si}$ and $\mathrm{Al}$ ions from aluminosilicate material to form geopolymer precursors and finally alumino-silicate material[14].

The most commonly used alkaline activators are $\mathrm{NaOH}$ and $\mathrm{Na}_{2} \mathrm{SiO}_{3}$ solutions. Compared to $\mathrm{NaOH}$ solution, $\mathrm{KOH}$ solution produced a greater level of alkalinity. But in reality, it has been found that $\mathrm{NaOH}$ possesses greater capacity to liberate silicate and aluminate monomers [15]. The potassium-based alkaline solutions are usually very costly and are not suitable for economic viability for the production of geopolymer materials. The sodium-based alkaline solutions are preferred and in such cases the formation of geopolymer matrix is also depended on its curing temperature. The curing of the product above normal atmospheric temperature is not a flexible option to adopt in commercial practice. Therefore, the selection of chemicals solution in alkaline group for geopolymerization reaction at atmospheric temperature has been the focus of research [16]. Usually this alkaline activator is prepared by mixing water, $\mathrm{NaOH}$ and $\mathrm{Na}_{2} \mathrm{SiO}_{3}$ but other alkali metal systems or mixtures of different alkalis also can also be used. The solution 
strictly needs to be concentrated to avoid the crystallization of zeolite as the end product rather than an amorphousgeopolymer[17, 18].

Joshi \&Kadu[19] prepared the alkaline activator using commercially available $\mathrm{Na}_{2} \mathrm{SiO}_{3}$ liquid and $\mathrm{NaOH}$ pellets which contain $\mathrm{Na}_{2} \mathrm{O}=14.61 \%, \mathrm{SiO}_{2}=25.18 \%$ and water $=$ $59.99 \%$. The alkaline solution was prepared with $\mathrm{NaOH}$ concentration varying from $8 \mathrm{M}$ to $16 \mathrm{M}$ and the mass ratio of $\mathrm{Na}_{2} \mathrm{SiO}_{3}$ to $\mathrm{NaOH}$ varied from 1.75 to 3.0. They found that the geopolymer with $14 \mathrm{M}$ and solid/liquid ratio 2.0 perform the optimum mechanical properties compared to others A study by Gharzouni et al. [20] stated the type of alkaline solution is important. The research found that the geopolymers based on a mixture of $\mathrm{K}_{2} \mathrm{SiO}_{3}$ and $\mathrm{KOH}$ display higher mechanical properties compared to those based on $\mathrm{Na}_{2} \mathrm{SiO}_{3}$ and $\mathrm{NaOH}$ or $\mathrm{K}_{2} \mathrm{SiO}_{3} / \mathrm{NaOH}$ mixtures.

\subsection{Manufacturing of geopolymer}

Geopolymer was usually prepared by mixing alumino-silicate or raw material with the alkaline activator solution. The raw materials previously were ground in a ring mill until fine particles were obtained [21]. The mixtures of alumino-silicate and alkali activator solution then formed slurry and was cured for 24 hours. Normally, the dissolution of sodium hydroxide was modified in one liter of distilled water in a volumetric flask to obtain a optimum molar concentration of $\mathrm{NaOH}$ [22]. Mustafa et al. [23] in his research mixed the raw material with an alkaline activator in the mixer. Further, the geopolymer was placed in the $50 \times 50 \times 50 \mathrm{~mm}^{3}$ mold and were cured at different curing temperatures.

The ratio of the raw material with the alkaline activator plays an important role in forming the geopolymer[24]. The $\mathrm{Si} / \mathrm{Al}$ composition for geopolymer prepared from raw material were 2.5 and 3.5 respectively [25]. At the same time, Cheng et al. [26], used $\mathrm{SiO}_{2} / \mathrm{Al}_{2} \mathrm{O}_{3}$ ratio in the range of 3.16-3.46. Mustafa et al. [27], in his research used 2.5 as ratio of $\mathrm{Na}_{2} \mathrm{SiO}_{3} / \mathrm{NaOH}$. Normally the ratio of solid to liquid $(\mathrm{S} / \mathrm{L})$ started from 0.6 and above.

\subsection{Dolomite}

Dolomite is one of the most common carbonate minerals in the geologic record. It is an anhydrous carbonate mineral composed of calcium, magnesium, and carbonate, ideally $\mathrm{CaMg}\left(\mathrm{CO}_{3}\right)_{2}$. The word dolomite is also used to describe the sedimentary carbonate rock, which is composed predominantly of the mineral dolomite (also known as dolostone). Dolomite is one of mineral resource that can be used as raw material ingeopolymer composites[28].The mineral dolomite will crystallize in the trigonal-rhombohedral system. It forms white, tan, gray, or pink crystals. Dolomite is a double carbonate, which having an alternating structural arrangement of calcium and magnesium ions. It does not rapidly dissolve in dilute hydrochloric acid as calcite does [29]. Table 1 display the chemical composition of dolomite. It contains small amount of alumina oxide $\left(\mathrm{Al}_{2} \mathrm{O}_{3}\right)$ andsilicon dioxide $\left(\mathrm{SiO}_{2}\right)$ composition that make it possible to be raw material for geopolymer It also contain high calcium oxide $(\mathrm{CaO})$ and magnesium oxide $(\mathrm{MgO})$ composition.

Table 1. Chemical composition of dolomite[29].

\begin{tabular}{|c|c|c|c|c|c|c|}
\hline $\mathrm{CaO}$ & $\mathrm{SiO}_{2}$ & $\mathrm{Al}_{2} \mathrm{O}_{3}$ & $\mathrm{Fe}_{2} \mathrm{O}_{3}$ & $\mathrm{MgO}$ & $\mathrm{K}_{2} \mathrm{O}$ & $\mathrm{Na}_{2} \mathrm{O}$ \\
\hline 33.4 & 2.5 & 0.7 & 0.3 & 17.1 & 0.1 & 0.1 \\
\hline
\end{tabular}

*loss of ignition: 45.8 


\section{Results and Discussion}

\subsection{Properties of Geopolymer Based on Dolomite}

\subsubsection{Compressive strength}

The properties of dolomite as substitution in metakaolingeopolymer were studied by Rodriguez-Blanco et al.[29]in terms of compressive strength. Fig.1 shows the compressive strength development of geopolymers with $20 \%$ replacement of metakaolin by dolomite.The activator modulus (Ms) of alkaline activator was also varied. The compressive strength of all samples increased gradually with ageing. The highest compressive strength $(45-55 \mathrm{MPa})$ is achieved with alkaline activator of $\mathrm{Ms}=1.5$. The strength development of the dolomite-containing systems was also significantly slower, particularly in samples with alkaline solution of $\mathrm{Ms}=1.2$ samples. From the compressive strengths of dolomite-containing binders are found to be consistently lower than that of the calcite-containing binders at all alkaline conditions studied.

Zarina et al.[30] investigates the influence of dolomite on the mechanical properties of boiler ash based geopolymer pastes. It was found that the addition of dolomite decreased the 28-day strength of boiler ash geopolymer. The geopolymer sample without addition of dolomite showed the maximum compressive strength $(19.4 \mathrm{MPa})$ at 28 days testing. Meanwhile the addition of $4 \%$ of dolomite into geopolymer paste achieved only maximum compressive strength of $7.3 \mathrm{MPa}$.

The dolomite particles used were larger than the calciteparticles, however their morphologies were not dramatically different. These differences are sufficient to cause the significant differences between the two minerals in geopolymerization as observed. The consistently lower compressive strength achieved by dolomite-containing systems is therefore most likely attributed to either a lower dissolved calcium level (calcite $=53.5$ while dolomite=33.4) or differences in surface properties of calcite and dolomite (the dolomite used here has a particle size roughly twice that of the calcite) [31, 32], which may affect the binding of the minerals to geopolymer gel.

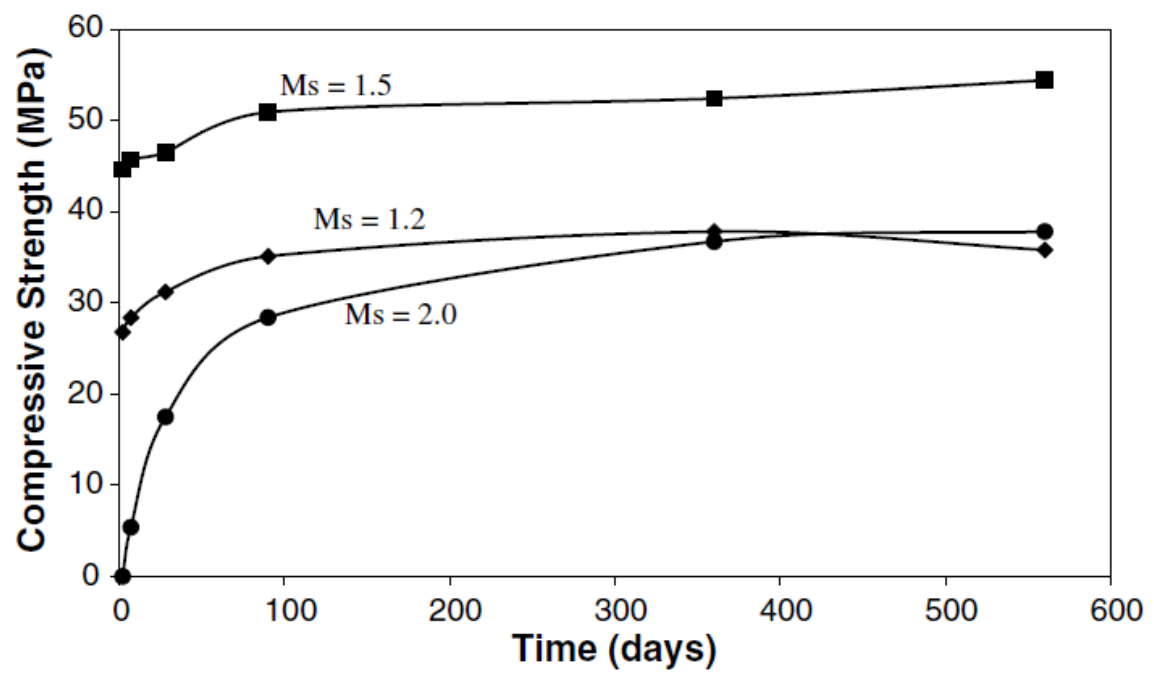

Fig.1. Compressive strength development of geopolymers with $20 \%$ dolomite and $80 \%$ metakaolin with varying Ms of alkaline activators [11, 29]. 


\subsubsection{X-ray diffraction analysis}

Fig.2 shows the XRD diffractogram of metakaolin-dolomite geopolymers. It was revealed that geopolymeric phase is the dominant product formed during alkali activation. This is again identified through the presence of an amorphous hump at around $20-35^{\circ} 2 \theta$, regardless of the alkalinity of the alkaline activator used [29]. There was also a significant amount of unreacted dolomite remained in the system. Thediffractograms exhibit slight reaction of dolomite, evidenced by diminution of the dolomite XRD peaks, which are more notable at $\mathrm{Ms}=1.2$ than $\mathrm{Ms}=2.0$ [33].

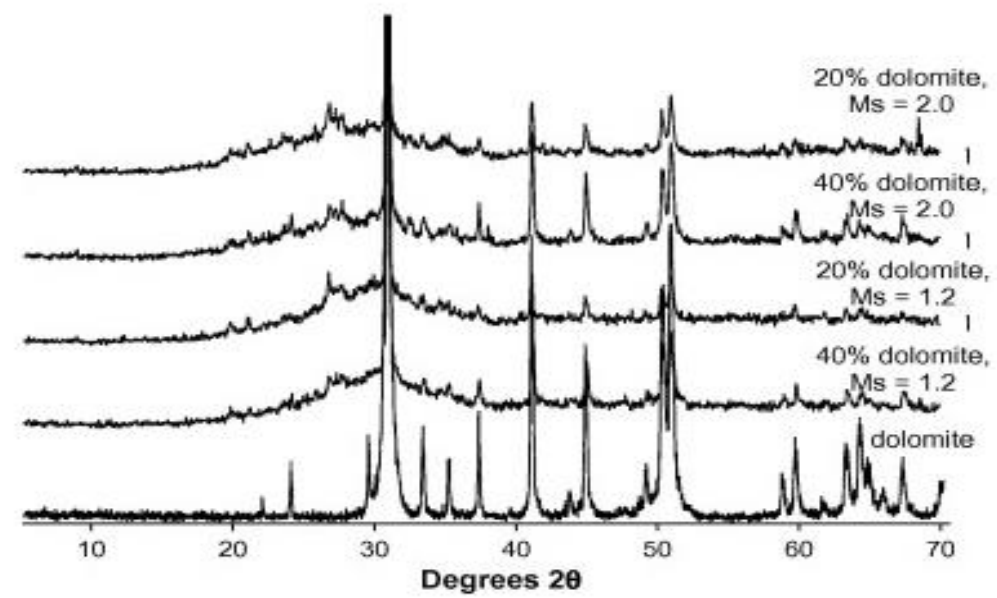

Fig.2. X-ray diffractograms of metkaolingeopolymers with $20 \%$ or $40 \%$ replacement by dolomite [29].

\subsubsection{Effect of magnesium content in Dolomite}

It has previously been noted that it is possible for magnesium ions to replace some fraction of the calcium ions in calcium silicate hydrate gels, or in fact to form magnesium silicate hydrate gels [34]. However, the fact that no distinct $\mathrm{C}-\mathrm{S}-\mathrm{H}$ phase has been observed throughout this study indicates that this mechanism is unlikely to be significant here for magnesium. It is therefore possible that $\mathrm{Mg}^{2+}$ plays a similar role to $\mathrm{Ca}^{2+}$ in situations where it is found within the geopolymeric gel phase [35]. Magnesium salts have been observed to have much less impact on geopolymerization kinetics than do their calcium counterparts, but do show some accelerating effect in geopolymeric setting which has been ascribed to nucleation effects[36].

Bakharev[37] done the study on the durability of geopolymer materials in magnesium sulfate solutions. SEM examination revealed formation of deep vertical cracks in the samples exposed to magnesium sulfate solutions. Ion chromatography indicated migration of alkali cations into solution. The analysis also indicated a decline of $\left[\mathrm{Mg}^{+2}\right]$ in testing solution in the samples, which may occur due to migration of $\mathrm{Mg}^{2+}$ into material. Bulk chemical variation across the specimens showed an increase of $\mathrm{Ca}, \mathrm{Mg}$ and $\mathrm{S}$ concentrations in the surface area, a slight decrease of Al content, while Si content stayed without change. Therefore, migration of $\mathrm{Ca}$ from inside of the specimen to the surface area, and $\mathrm{S}$ and $\mathrm{Mg}$ from the solution into aluminosilicate matrix can be suggested[38].

The SEM image of fracture surface shown formation of lightly coloured precipitates in the surface area of the samples exposed to magnesium sulfate solution. In these case, the 
diffusion of $\mathrm{Mg}$ into material occurred at the same time as migration of alkali ions from samples into solution. These processes are responsible for fluctuations of the compressive strength and final strength improvement of the samples when immersed in the magnesium sulfate solution. $\mathrm{Ca}^{+2}$ and $\mathrm{Mg}^{+2}$ ions can be accommodated in aluminasilicate gel as network-modifying cations [39].

\section{Conclusions}

This paper summarizes the suitability of dolomite to be used as geopolymer materials. Based on the reviewed literature above, dolomite was used as a replacement to the main raw materials (e.g. metakaolin) in the synthesis of geopolymers. There are limited studies using dolomite as the aluminosilicate materials. Hence, the used of dolomite as precursor material in geopolymer material is still new and further study must be done to investigate the properties of geopolymer system based on dolomite. Besides, the use of dolomite which is abundantand potentially offer sustainable solution and environmental friendly for extending the service life of infrastructure and maintenance cost.Development of dolomite geopolymeris less been explored. It is hoped that future research in this field will drive a new era of greener materials in the geopolymer industry.

\section{References}

1. P.K. Sarker, S. Kelly, Z. Yao, Mater. Design, 63, 584 (2014)

2. L. Zeng, C. Dan-yang, Y. Xu, F. Chun-wei, P. Xiao-Qin, Appl. Clay Sci., 101, 637 (2014)

3. P. Duxson, A. Fernandez-Jimenez, J.L. Provis, G.C. Lukey, A. Palomo, J.S.J. Van Deventer, J. Mater. Sci., 42, 2917 (2007)

4. J. Temuujin, A. Minjigmaa, W. Rickard, A. Van Riessen, J. Therm. Anal. Calorim., 107, 287 (2012)

5. J. Liyana, H. Kamarudin, A.M. Mustafa AlBakri, M. Binhussain, C.M. Ruzaidi, A.M. Izzat, Aust. J. Basic \& Appl. Sci, 2, 100 (2013)

6. M. Sofi, J. van Deventer, P. Mendis, G. Lukey, J. Mater. Sci., 42, 3107 (2007)

7. J.L. Bell, P.E. Driemeyer, W.M. Kriven, J. Am. Ceram. Soc., 92, 607 (2009)

8. T. Alomayri, F.U.A. Shaikh, I.M. Low, Ceram. Int., 40, 14019 (2014)

9. J. Davidovits, J. Mater. Educ., 16, 91 (1994)

10. J.Temuujin, A. Minjigmaa, W. Rickard, M. Lee, I. Williams, A. Van Riessen, J. Hazard. Mater., 180, 748 (2010)

11. C.K. Yip, J.L. Provis, G.C. Lukey, J.S.J. Van Deventer, Cement Concrete Comp., 30, 979 (2008)

12. S.H. Sanni, R. Khadiranaikar, International Journal of Research in Engineering and Technology, 2, 100 (2013)

13. B. Singh, G. Ishwarya, M. Gupta, S.K. Bhattacharyya, Constr. Build. Mater., 85, 78 (2015)

14. A. Fernandez-Jimenez, A. Palomo, Fuel, 82(18), 2259 (2003)

15. P. Duxson, A. Fernandez-Jimenez, J. Provis, G. Lukey, A. Palomo, J. Van Deventer, J. Mater. Sci., 42, 2917 (2007)

16. D. Khale, R. Chaudhary, J. Mater. Sci., 42, 729 (2007)

17. J. Davidovits, 99 International Conference. Saint-Quentin, France (1999)

18. D. Hardjito, Studies of fly ash-based geopolymer concrete, Curtin University of Technology (2005) 
19. S. Joshi, M. Kadu, International Journal of Environment and Sustainable Development, 3, 100 (2012)

20. A. Gharzouni, E. Joussein, B. Samet, S. Baklouti, S. Rossignol, J. Non-Cryst. Solids, 410, 127 (2015)

21. C. Tippayasam, P. Keawpapasson, P. Thavorniti, T. Panyathanmaporn, C. Leonelli, D. Chaysuwan, Constr. Build. Mater., 53, 455 (2014)

22. A.M. Mustafa Al Bakri, L. Jamaludin, H. Kamarudin, M. Binhussain, M.C. Ruzaidi, A.M. Izzat, Adv. Mat. Res., 686, 227 (2013)

23. A.M. Mustafa Al Bakri, , H. Kamarudin, M. Binhussain, I.K. Nizar, Y. Zarina, A.R. Rafiza, Phys. Procedia, 22, 286 (2011)

24. E. Kamseu, B. Nait-Ali, M.C. Bignozzi, C. Leonelli, S. Rossignol, D.S. Smith, J. Eur. Ceram. Soc., 32, 1593 (2012)

25. Z. Zhang, X. Yao, H. Zhu, Appl. Clay. Sci., 49, 1 (2010)

26. T. Cheng, J. Chiu, Miner. Eng., 16, 205 (2003)

27. A.M. Mustafa Al Bakri, L. Jamaludin, K. Hussin, M. Bnhussain, C.M. Ruzaidi, A.M. Izzat, Int. J. Mol. Sci., 13, 4388 (2012)

28. C.M. Pina, Am. Mineral., 100, 1017 (2015)

29. J.D. Rodriguez-Blanco, S. Shaw, L.G. Benning, Am. Mineral., 100, 1172 (2015)

30. Y. Zarina, H. Kamarudin, A.M.M. Al Bakri, I. Khairul Nizar, A.R. Rafiza, Key Eng. Mat., 594, 8 (2014)

31. K. Wright, R.T. Cygan, B. Slater, Phys. Chem. Chem. Phys., 3, 839 (2001)

32. P. Fenter, Z. Zhang, C. Park, N.C. Sturchio, X.M. Hu, S.R. Higgins, Geochim. Cosmochim. Acta, 71, 566 (2007)

33. K. Wang, X. Hu, P. Zhao, Z. Yin, Appl. Energy., 165, 14 (2016)

34. F.P. Glasser, J. Hazard. Mater., 52, 151 (1997)

35. D.R.M. Brew, F.P. Glasser, Cement Concrete Res., 35, 85 (2005)

36. W.K.W. Lee, J.S.J. Van Deventer, Cement Concrete Res., 32, 577 (2002)

37. T. Bakharev, Cement Concrete Res., 35, 1233 (2005)

38. D.Bonen, M.D. Cohen, Cement Concrete Res., 22, 707 (1992)

39. D.Perera, M. Blackford, E. Vance, J. Hanna, K. Finnie, C. Nicholson, MRS Proceedings, 824, 35 (2004) 